\title{
Genetic Variability, Heritability and Genetic Advance for Different Traits in China Aster Varieties
}

\author{
D. Naikwad*, K. Kandpal, A. Hugar, M.G. Patil and V. Kulkarni \\ Department of Horticulture, College of Agriculture, University of Agricultural Sciences, \\ Raichur-584102, Karnataka, India \\ *Corresponding author
}

\section{A B S T R A C T}

\begin{tabular}{|l|}
\hline K e y w o r d s \\
China aster, \\
Phenotypic \\
Coefficients of \\
Variation (PCV), \\
Genotypic \\
Coefficients of \\
Variation (GCV), \\
Heritability, Genetic \\
advance as percentage \\
of mean (GAM)
\end{tabular}

\section{Introduction}

China aster [Callistephus chinensis (L.) Nees] belongs to one of the largest families of flowering plants, 'Asteraceae'. The present day asters have been developed from a single form of wild species known as, Callistephus chinensis. The name of the genus 'Callistephus' is derived from two Greek words 'kalistos' meaning 'most beautiful' and 'stephos', a crown, referring to the flower head. The genus Callistephus has only a single species, namely, Callistephus chinensis. It is native to China and has spread to European countries and other tropical countries during 1731 AD (Desai, 1967). China aster is one of the most important annual flower crops grown in most parts of the world.

The evolution of China aster [Callistephus chinensis (L.) Nees] has a history of remarkable variations. According to Emsweller et al., (1937), the original plant 
had single flowers with two or four rows of blue, violet or white ray florets. The stature was medium tall and height of the plant ranged from 18 to 24 inches. The first change in the flower type had been the prolongation or development of central florets and the production of quilled flowers. Germans developed double forms in aster during $18^{\text {th }}$ century. Hence, asters are also called as German asters. Advancement of the aster evolution and large scale seed production by Germans led to the introduction of branching types, tall types, medium tall and dwarf types and this contributed for great evolutionary improvement in China aster.

\section{Materials and Methods}

The experiment was carried out in Randomized Block Design with three replications in the Experimental block of Department of Horticulture, College of Agriculture, UAS, Raichur during the year of 2016-17. Twelve different varieties viz., Kamini, Shashank, Poornima, Arka Aadya, Arka Archana, Phule Ganesh White, Phule Ganesh Pink, Phule Ganesh Purple, Phule Ganesh Violet, Mudigere Local, Namdhari Pink and Namdhari White were used for the study. Spacing of $50 \mathrm{~cm}$ between replications and $30 \mathrm{~cm}$ between two plots were provided for laying out the bunds. The entire experimental land was divided into subplots measuring $3.6 \mathrm{~m} \mathrm{x} 3.0 \mathrm{~m}$ and there were totally 36 plots. Forty days old healthy and uniformly grown seedlings were transplanted with a spacing of $30 \times 30 \mathrm{~cm}$. The optimum irrigation was given soon after transplanting. Five randomly selected competitive plants from each replication for sixteen quantitative traits were selected.

The observations were recorded on quantitative characters selected for genetic variability studies such as plant height $(\mathrm{cm})$, plant spread $(\mathrm{cm})$, Number of leaves, Number of primary branches, Number of secondary branches, Leaf area $\left(\mathrm{cm}^{2}\right)$, Leaf area index, Dry matter (g), Days to flower bud initiation, Days to flowering, Days for 50\% flowering, Duration of flowering (days), Number of flowers/plant, Flower diameter $(\mathrm{cm})$, Test weight (g) and yield/plant.

\section{Genetic variability, heritability and genetic advance}

Genetic variability is the basis of all crop improvement programmes. Higher the amount of variability in the population, greater is the scope for its improvement by selection. The importance of genetic variability was perceived by Vavilov (1951) for the first time and advocated that wide range of variability provides better scope for selecting a desirable genotype. Knowledge of heritability for different traits seems to be essential for any crop improvement programme because the heritable component is the consequence of genotype and is inherited from generation to generation. Wright (1921) reported that heritability comprised of additive and nonadditive components and it is the former which respond to selection.

The different genetic parameters should follow in order to evaluate and assess the genetic variability among the various genotypes by adopting following formulae.

\section{Estimation of variance component}

Genotypic and phenotypic components of variance were estimated with the help of following formulae.

$$
\begin{gathered}
\text { MSS (treatment) - MSS } \\
\text { (error) }
\end{gathered}
$$

Genotypic variance $\left(\sigma^{2} \mathrm{~g}\right)=\overline{\text { Number of replications }}$

Phenotypic variance $\left(\sigma^{2} p\right)=\sigma^{2} g+$ MSS (error) 


\section{Co-efficient of variation}

Both genotypic and phenotypic coefficients were computed for each character as per the method suggested by Burton and Devane (1953).

Genotypic coefficient of variability $(\mathrm{GCV})=$

$$
\frac{\sigma \mathrm{g}}{\bar{X}^{-}} * 100
$$

Phenotypic coefficient of variability $(\mathrm{PCV})=$

$$
\frac{\sigma \mathrm{p}}{\overline{\mathrm{X}}} \times 100
$$

Where,

$\sigma \mathrm{g}=$ Genotypic standard deviation

$\sigma \mathrm{p}=$ Phenotypic standard deviation

$\overline{\mathrm{X}}=$ General mean of character

GCV and PCV values were categorized as low, moderate and high values as suggested by Sivasubramanian and Menon (1973), which is as follows:

\section{1-10 per cent : Low \\ 10.1-20 per cent : Moderate \\ 20.1 per cent and above : High}

\section{Heritability $\left(\mathbf{h}^{2} \mathbf{b}\right)$}

Heritability in broad sense was computed as the ratio of the total phenotypic variance as suggested by Hanson et al., (1956) and expressed in terms of percentage.

Heritability $\left(h^{2}\right)=\frac{\sigma^{2} g}{\sigma^{2} p} \times 100$

Where,

$\sigma^{2} \mathrm{~g}=$ Genotypic variance

$\sigma^{2} \mathrm{p}=$ Phenotypic variance
The heritability percentage was categorized as low, moderate and high as given by Robinson et al., (1949).

0-30 per cent : Low

30.1-60 per cent : Moderate

60.1 per cent and above : High

\section{Genetic advance (GA)}

Genetic advance was estimated by using the formula given by Johnson et al., (1955).

$\mathrm{GA}=\mathrm{h}^{2} \mathrm{k} \sigma \mathrm{p}$

Where,

$\mathrm{h}^{2}=$ Heritability in broad sense

$\mathrm{k}=$ Selection deferential which is equal to 2.06 at 5\% intensity of selection (Lush, 1940)

$\sigma p=$ Phenotypic standard deviation

Genetic advance as per cent of mean (GAM)

$\mathrm{GAM}=\frac{\mathrm{GA}}{\mathrm{X}^{-}} \times 100$

Where,

$\mathrm{GA}=$ Genetic advance

$\mathrm{X}=$ General mean of the character

Genetic advance as per cent mean was categorized as low, moderate and high as given by Johnson et al., (1955).

It is as follows,

10.1-20 per cent

: Low

20.1 per cent and above

: Moderate

: High

\section{Results and Discussion}

Analysis of variance showed significant differences among the genotypes for all the 
sixteen quantitative parameters, indicating the sufficient genetic variability to be exploited in breeding programme (Table 1).

A knowledge of the estimates of genotypic coefficient of variation (GCV), phenotypic coefficient of variation (PCV), heritability $\left(h^{2} b\right)$ and genetic advance as percentage of mean (GAM) would help the breeder in selection of appropriate breeding methods. The interaction of number of component characters may result in boosting the yield of the crop.

\section{Genetic variability studies}

\section{Coefficients of variation}

Genetic parameters viz., range, mean, genotypic co-efficient of variation (GCV), phenotypic co-efficient variation (PCV), heritability $\left(\mathrm{h}^{2}\right)$ and genetic advance as per cent of mean (GAM) were calculated to estimate the extent of genetic variability for 16 characters and the results are presented in Table 2 (Fig. 1).

\section{Plant height}

Plant height ranged from $34.70 \mathrm{~cm}$ to 64.92 $\mathrm{cm}$ with mean value of $49.81 \mathrm{~cm}$, with the estimated GCV and PCV of 22.78 and 23.85 per cent, respectively. The highest heritability recorded by this trait was 91.2 per cent, whereas the genetic advance over mean was observed 44.81 per cent.

\section{Plant spread}

Plant spread ranged from $16.61 \mathrm{~cm}$ to 32.00 $\mathrm{cm}$ with mean value of $24.31 \mathrm{~cm}$, with estimated GCV and PCV of 15.46 and 16.71 per cent, respectively. The highest heritability recorded by this trait was 85.50 per cent, while the genetic advance over mean was found to be 29.46 per cent.

\section{Number of leaves}

The minimum number of leaves was recorded 129.11, while maximum number of leaves was 182.06 with mean of 155.59 . GCV of 11.03 per cent and PCV of 12.13 per cent were recorded for this trait. Heritability value of 82.70 per cent and genetic advance over mean was 20.66 per cent noticed for the character.

\section{Number of primary branches}

It ranged from 11.05 to 19.16 with mean value of 15.11, with estimated GCV and PCV of 15.31 and 18.88 per cent, respectively. The highest heritability recorded by this trait was 65.70 per cent, while the genetic advance over mean was 25.58 per cent.

\section{Number of secondary branches}

It ranged from 19.20 to 37.21 with mean value of 28.21 and estimated GCV and PCV of 20.39 and 20.66 per cent, respectively. The highest heritability recorded by this trait was 97.40 per cent, while the genetic advance over mean was noticed as 41.47 per cent.

\section{Leaf area}

Leaf area ranged from $18.87 \mathrm{~cm}^{2}$ to 36.32 $\mathrm{cm}^{2}$ with mean value of $27.60 \mathrm{~cm}^{2}$. The estimated GCV and PCV of 22.83 and 23.44 per cent, respectively were recorded. The highest heritability recorded by this trait was 94.90 per cent, while the genetic advance over mean was observed 45.83 per cent.

\section{Leaf area index}

It ranged from 0.02 to 0.04 with mean value of 0.03 with estimated GCV and PCV of 21.10 and 21.70 per cent, respectively. The highest heritability recorded by this trait was 94.50 per cent, while the genetic advance over mean was recorded 42.25 per cent. 


\section{Dry matter}

Dry matter ranged from 34.31 to $48.02 \mathrm{~g}$ plant $^{-1}$ with mean value of $41.17 \mathrm{~g}$ plant $^{-1}$, while estimated GCV and PCV of 8.76 and 10.12 per cent, respectively were recorded. The highest heritability recorded by this trait was 75.00 per cent, while the genetic advance over mean was noticed 15.64 per cent.

\section{Days to flower bud initiation}

It ranged from 26.10 days to 63.33 days with mean value of 44.72 days. The estimated GCV and PCV of 26.22 and 26.86 per cent, respectively were recorded. The highest heritability recorded by this trait was 95.30 per cent, while the genetic advance over mean was recorded 52.75 per cent.

\section{Days to flowering}

The number of days to flowering for the genotypes ranged from 30.60 to 73.33 days with a mean value of 51.97 days. For this trait the GCV and PCV were found to be 25.38 and 26.08 per cent, respectively with very high heritability of 94.70 per cent. Genetic advance as per cent of mean of 50.86 per cent was recorded.

\section{Days to $50 \%$ flowering}

The number of days to 50 per cent flowering for the genotypes ranged from 55.33 to 79.00 days with a mean value of 67.17 days for this trait the GCV and PCV were found to be 12.12 and 12.36 per cent, respectively with very high heritability of 96.00 per cent. Genetic advance as per cent of mean of 24.46 per cent was recorded.

\section{Duration of flowering}

Duration of flowering ranged from 26.00 to 34.44 days with a mean value of 30.22 days.
For this trait the GCV and PCV were found to be 7.26 and 10.52 per cent, respectively with medium heritability of 47.00 per cent. Low genetic advance as per cent of mean was recorded 10.33 per cent.

\section{Number of flowers/plant}

It ranged from 39.00 to 68.53 with mean value of 53.77, with the estimated GCV and PCV of 17.57 and 18.53 per cent, respectively. The highest heritability recorded by this trait was 89.00 per cent, while the genetic advance over mean was recorded 34.33 per cent.

\section{Size of the flower (diameter)}

The average size of the flower ranged from $3.77 \mathrm{~cm}$ to $6.35 \mathrm{~cm}$ with a mean value of 5.06 and the estimated GCV and PCV of 16.69 and 17.52 per cent, respectively. The highest heritability recorded by this trait was 90.70 per cent, while the genetic advance over mean was recorded 32.76 per cent.

\section{Test weight}

The average test weight of fresh flowers ranged from $19.51 \mathrm{~g}$ to $55.33 \mathrm{~g}$ with mean value of $37.42 \mathrm{~g}$, while the estimated GCV and PCV of 42.15 and 42.47 per cent, respectively were recorded. The highest heritability recorded by this trait was 98.50 per cent, while the genetic advance over mean was noticed 86.18 per cent.

\section{Yield per plant (g)}

Yield per plant ranged from $88.01 \mathrm{~g}$ to 214.67 $\mathrm{g}$, the average value being $151.34 \mathrm{~g}$, with the estimated GCV and PCV of 29.88 and 30.36 per cent, respectively. The highest heritability recorded by this trait was 96.90 per cent, whereas the genetic advance over mean was observed 60.59 per cent. 
Table.1 Analysis of variance for quantitative characters of various China aster genotypes

\begin{tabular}{|c|c|c|c|c|}
\hline \multirow{3}{*}{$\begin{array}{c}\text { Sl. } \\
\text { No. }\end{array}$} & \multirow[b]{2}{*}{ Source of variation/ parameters } & \multicolumn{3}{|c|}{ Mean sum of squares } \\
\hline & & Replication & Genotypes & Error \\
\hline & Degrees of freedom & 2 & 11 & 22 \\
\hline 1 & Plant height $(\mathrm{cm})$ & 14.7 & $301.70 *$ & 9.4 \\
\hline 2 & Plant spread $(\mathrm{cm})$ & 1.6 & $53.20 *$ & 2.8 \\
\hline 3 & Number of leaves & 92.19 & $896.54 *$ & 58.49 \\
\hline 4 & Number of primary branches & 0.65 & $18.33 *$ & 2.71 \\
\hline 5 & Number of secondary branches & 12.82 & $97.28 *$ & 2 \\
\hline 6 & Leaf area $\left(\mathrm{cm}^{2}\right)$ & 36.87 & $98.09 *$ & 1.72 \\
\hline 7 & Leaf area index & 0 & $0.0001 *$ & 0 \\
\hline 8 & Dry matter $(\mathrm{g})$ & 87.7 & $43.60 *$ & 4.3 \\
\hline 9 & Days to flower bud initiation & 14.1 & $454.40^{*}$ & 7.3 \\
\hline 10 & Days to flowering & 8.7 & $573.20 *$ & 10.6 \\
\hline 11 & Days for $50 \%$ flowering & 0.4 & $215.20^{*}$ & 11.8 \\
\hline 12 & Duration of flowering (days) & 38.6 & $21.70 *$ & 5.8 \\
\hline 13 & Number of flowers/plant & 12.2 & $275.00^{*}$ & 9.9 \\
\hline 14 & Yield/plant (g) & 90 & $5833.70 *$ & 62.4 \\
\hline 15 & Flower diameter $(\mathrm{cm})$ & 0.2 & $2.20 *$ & 0.1 \\
\hline 16 & Test weight (g) & 0.4 & $510.70 *$ & 2.6 \\
\hline
\end{tabular}

*Significant at $5 \%$ probability 
Table.2 Estimates of phenotypic and genotypic coefficients of variation, heritability and genetic advance for different traits in China aster

\begin{tabular}{|c|c|c|c|c|c|c|c|c|}
\hline \multirow{2}{*}{$\begin{array}{c}\text { Sl. No } \\
1\end{array}$} & \multirow{2}{*}{$\begin{array}{l}\text { Characters } \\
\text { Plant height }(\mathrm{cm})\end{array}$} & \multicolumn{2}{|c|}{ Range } & \multirow{2}{*}{$\begin{array}{l}\text { Mean } \\
49.81\end{array}$} & \multirow{2}{*}{$\begin{array}{c}\text { GCV (\%) } \\
22.78\end{array}$} & \multirow{2}{*}{$\begin{array}{c}\text { PCV (\%) } \\
23.85\end{array}$} & \multirow{2}{*}{$\begin{array}{c}\mathbf{h}_{\text {BS }}^{\mathbf{2}}(\boldsymbol{\%}) \\
91.20\end{array}$} & \multirow{2}{*}{$\begin{array}{c}\text { GAM (\%) } \\
44.81\end{array}$} \\
\hline & & 34.70 & 64.92 & & & & & \\
\hline 2 & Plant spread $(\mathrm{cm})$ & 16.61 & 32.00 & 24.31 & 15.46 & 16.71 & 85.50 & 29.46 \\
\hline 3 & Number of leaves & 129.11 & 182.06 & 155.59 & 11.03 & 12.13 & 82.70 & 20.66 \\
\hline 4 & Number of primary branches & 11.05 & 19.16 & 15.11 & 15.31 & 18.88 & 65.70 & 25.58 \\
\hline 5 & Number of secondary branches & 19.20 & 37.21 & 28.21 & 20.39 & 20.66 & 97.40 & 41.47 \\
\hline 6 & Leaf area $\left(\mathrm{cm}^{2}\right)$ & 18.87 & 36.32 & 27.60 & 22.83 & 23.44 & 94.90 & 45.83 \\
\hline 7 & Leaf area index & 0.02 & 0.04 & 0.03 & 21.10 & 21.70 & 94.50 & 42.25 \\
\hline 8 & Dry matter (g) & 34.31 & 48.02 & 41.17 & 8.76 & 10.12 & 75.00 & 15.64 \\
\hline 9 & Days to flower bud initiation & 26.10 & 63.33 & 44.72 & 26.22 & 26.86 & 95.30 & 52.75 \\
\hline 10 & Days to flowering & 30.60 & 73.33 & 51.97 & 25.38 & 26.08 & 94.70 & 50.86 \\
\hline 11 & Days for $50 \%$ flowering & 55.33 & 79.00 & 67.17 & 12.12 & 12.36 & 96.00 & 24.46 \\
\hline 12 & Duration of flowering (days) & 26.00 & 34.44 & 30.22 & 7.26 & 10.52 & 47.00 & 10.33 \\
\hline 13 & Number of flowers/plant & 39.00 & 68.53 & 53.77 & 17.57 & 18.53 & 89.00 & 34.33 \\
\hline 14 & Flower diameter $(\mathrm{cm})$ & 3.77 & 6.35 & 5.06 & 16.69 & 17.52 & 90.70 & 32.76 \\
\hline 15 & Test weight (g) & 19.51 & 55.33 & 37.42 & 42.15 & 42.47 & 98.50 & 86.18 \\
\hline 16 & Yield/plant (g) & 88.01 & 214.67 & 151.34 & 29.88 & 30.36 & 96.90 & 60.59 \\
\hline
\end{tabular}

PCV-Phenotypic co-efficient of variance GAM- Genetic advance as per cent of mean 
Fig.1 Genotypic and phenotypic coefficient of variation for sixteen characters in China aster

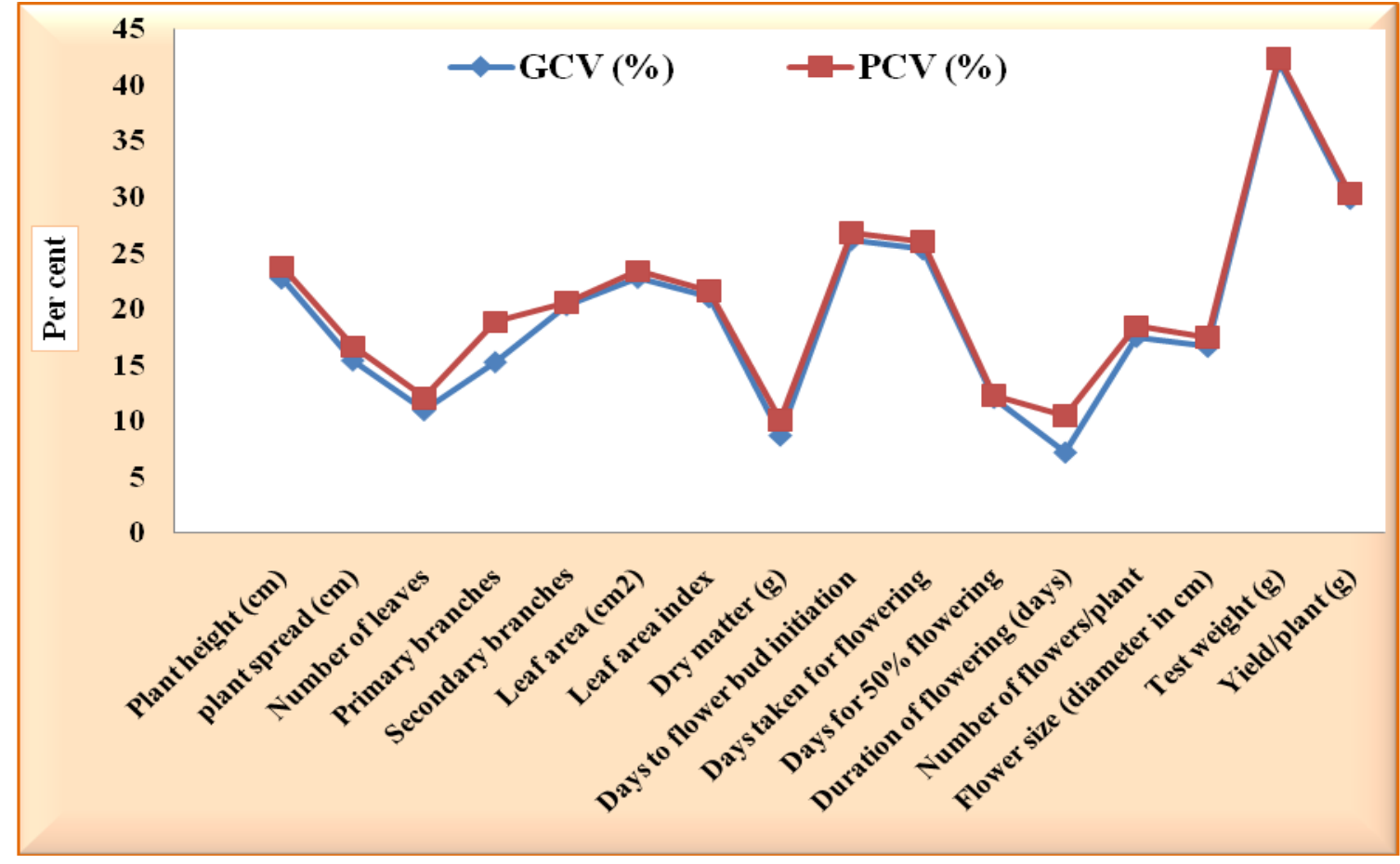

Fig.2 Heritability estimates and genetic advances over mean for sixteen characters in China aster

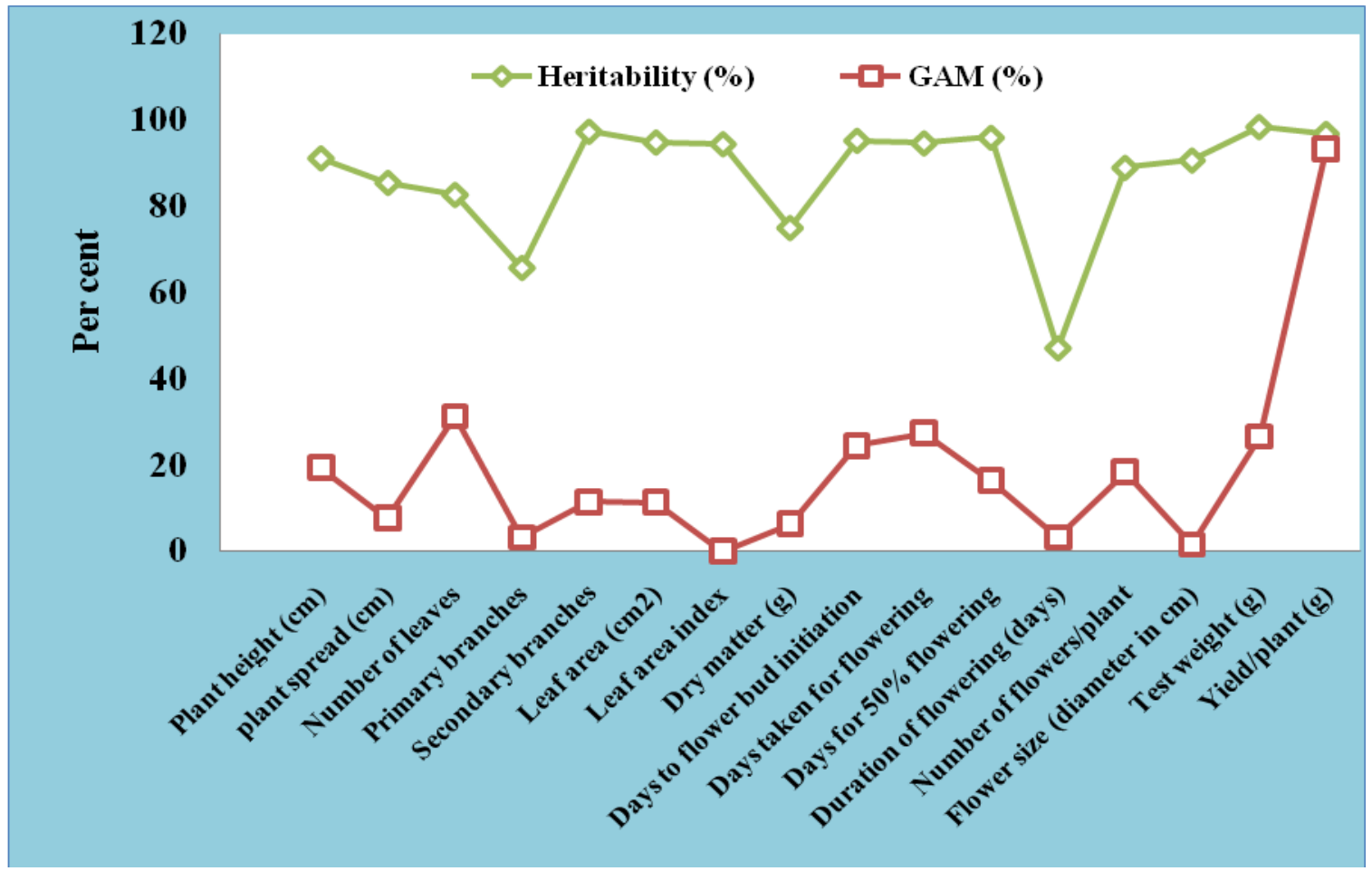




\section{Genetic variability studies}

\section{Coefficients of variation}

The phenotypic variance measures the magnitude of variation arising out differences in phenotypic values while, the genotypic variance measures the magnitude of variation arising out differences in genotypic values. As the phenotypic genotypic variance in absolute values cannot be used to compare magnitude of variability of different growth and yield parameters. Hence, these parameters are converted into co-efficient of variance at genotypic and phenotypic levels.

The estimates of phenotypic and genotypic coefficients of variation gave a clear picture of amount of variations present in the available varieties. For all the characters studied, phenotypic coefficients of variation were higher in magnitude than genotypic coefficients of variation, though difference was very less in majority the case. Thus, showing these traits were less influenced by environmental factors. Coefficients of variation varied in magnitude from character to character (either low or moderate or high). The higher magnitude of genetic coefficient of variation showing narrow difference between PVAR and GVAR indicates simple selection procedure would be sufficient to improve such traits in China aster.

The phenotypic coefficients of variation (PVAR) was found high for test weight, yield per plant, flower bud initiation, days to flowering, plant height, leaf area, leaf area index and number of secondary branches whereas moderate PVAR was found for number of flowers, flower size, plant spread, number of primary branches, days to 50 per cent flowers, number of leaves, dry matter and duration of flowering. Similar results for phenotypic coefficients of variation were observed by Kumar et al., (2003), Pal and George (2002), Nandakishore and Raghava
(2001), Sirohi and Behera (2000) and Singh and Sen (2000). Genotypic coefficients of variation (GVAR) was found high for test weight, yield per plant, flower bud initiation, days to flowering, plant height, leaf area, leaf area index and secondary branches whereas moderate GVAR was observed for number of flowers, flower size, plant spread, primary branches, days to 50 per cent flowers, number of leaves, while it was recorded low for dry matter and duration of flowering. Similar results for genotypic coefficients of variation were observed by Kumar et al., (2003), Pal and George (2002), Nandakishore and Raghava (2001), Sirohi and Behera (2000) and Singh and Sen (2000).

\section{Heritability}

The genotypic coefficient of variation does not offer full scope to estimate the variations that are heritable and therefore, estimation of heritability becomes necessary. Burton and De Vane (1953) had suggested that genetic coefficient of variation along with heritability estimates would give a reliable indication of expected amount of improvement through selection.

The estimates of heritability (broad sense) varied from 47.00 - $98.50 \%$ for different characters under study. It was found high for all the traits viz., test weight, number of secondary branches, yield per plant, days to 50 per cent flowers, days to flower bud initiation, leaf area, days to flowering, leaf area index, plant height, flower size, number of flowers per plant, plant spread, number of leaves, dry matter and primary branches except duration of flowering whereas, medium heritability was observed for duration of flowering. Kumar et al., (2003), Pal and George (2002), Nandakishore and Raghava (2001) and Singh and Sen (2000) also did similar kind of studies and found similar results (Fig. 2). 


\section{Genetic advance as per cent of mean}

High heritability estimates coupled with high genetic advance over mean was observed for test weight, yield per plant, days to flowering, days to flower bud initiation, leaf area, plant height, leaf area index, number of secondary branches, number of flowers per plant, flower size, plant spread, number of primary branches, days to 50 per cent flowering and number of leaves and the moderate genetic advance were recorded for dry matter and duration of flowering. Similar results were also observed Singh and Sen (2000), Nandakishore and Raghava (2001) and Pal and George (2002).

\section{Acknowledgement}

To the University of Agricultural Sciences, College of Agriculture Raichur for providing research facilities is gratefully acknowledged.

\section{References}

Burton, G. W. and Devane, E. M., 1953, Estimating heritability in tall fescue (Festuca arundinacea) from replicated clonal material. Agro. J., 45: 478-481.

Desai, B. L., 1967, Flower description in China aster (Callistephus chinensis). In: Seasonal flowers. ICAR Publication, New Delhi, pp. 53-56.

Emsweller, S. L., Brierley, P., Lumsden, D. V. and Mulferd, F. L., 1937, Breeding of ornamental plants. USDA Year Book of Agriculture, U. S. Dept. of Agriculture, pp. 926-929.
Hanson, G. H., Robinson, H. F. and Comstock, R. E., 1956, Biometrical studies of yield in segregating population of Korean Lespedeza. Agron. J., 48: 267-282.

Johnson, H. W., Robinson, H. F. and Constock, R. E. 1955, Estimates of genetic and environmental variability in soybean. Agron. J., 47: 314-319.

Kumar, H., Ravi and Paul, V. S., 2003, Genetic variability and character association studies in China aster (Callistephus chinensis) genotypes. J. Orn. Hort., 6 (3): 222-228.

Nandakishore and Raghava, S. P. S., 2001, Variability studies in African marigold. J. Orn. Hort., (New Series), 4 (2): 124-125.

Pal, P. and George, S. V., 2002, Genetic variability and correlation studies in chrysanthemum. Hort. J., 15 (2): 75 81.

Singh, D. and Sen, N. L., 2000, Genetic variability, heritability and genetic advance in marigold. J. Orn. Hort., (New series), 36 (2): 75-78.

Sirohi, P. S. and Behera, T. K., 2000, Genetic variability in chrysanthemum. J. Orn. Hort., (New series), 3 (1): 34-36.

Vavilov, N. I., 1951, The origin, variation, immunity and breeding of cultivated plants. Chronica Bot., 13: 366 p.

Wright, S., 1921, Correlation and causation. J. Agri. Res., 20: 557-585.

Sivasubramanian, V. and Menon, M. P. 1973, Path analysis for yield and yield components of rice. Madras Agril. J., 60: 1217-1221.

\section{How to cite this article:}

Naikwad, D., K. Kandpal, A. Hugar, M.G. Patil and Kulkarni, V. 2018. Genetic Variability, Heritability and Genetic Advance for Different Traits in China Aster Varieties. Int.J.Curr.Microbiol.App.Sci. 7(04): 3329-3338. doi: https://doi.org/10.20546/ijcmas.2018.704.377 